\title{
PEDAGOGIA FREIRIANA E PEDAGOGIAS FEMINISTAS: (DES)ENCONTROS E DIÁLOGOS (IM)POSSÍVEIS?
}

DOI: 10.48075/ri.v23i1.26306

Eunice Macedo ${ }^{1}$

RESUMO: Este artigo propõe cruzamentos e diálogos entre a pedagogia freiriana e as pedagogias feministas, como tradições teóricas e metodológicas emancipatórias da voz. A discussão assenta na proposta filosófica política de educação de Freire e de teóricas feministas como bell hooks e Iris Young, Marijke de Koning, e mesmo Kathleen Weiler, com maior ou menor proximidade à ideação freiriana. Começo por auscultar possibilidades de diálogo entre estas tradições. Passo a situar a educação libertadora como política localizada que vai além do tempo e do lugar para, no ponto seguinte, provocar o encontro entre a ideação freiriana e feminista. Por último, discutem-se princípios das pedagogias feministas como corporização e enraizamento do movimento feminista, que permitem identificar pegadas de Freire.

Palavras-chave: Pedagogia freiriana; pedagogias feministas; tradições emancipatórias da voz.

\section{FREIRIAN PEDAGOGY AND FEMINIST PEDAGOGIES: (MIS)MATCHES AND (IM)POSSIBLE DIALOGUES?}

ABSTRACT: This article proposes crossings and dialogues between Freirian pedagogy and feminist pedagogies, as emancipatory theoretical and methodological traditions of voice. The discussion is based on the philosophical political proposal of education by Freire and feminist theorists such as bell hooks and Iris Young, Marijke de Koning, and even Kathleen Weiler, with greater or lesser proximity to Freire's ideation. I begin by listening to possibilities for dialogue between these traditions. I move to place liberating education as a localized policy that goes beyond time and place to provoke, in the next point, the encounter between Freirian and feminist ideation. Finally, the principles of feminist pedagogies are discussed, as embodiment and rooting of the feminist movement, which allow the identification of Freire's footprints.

Key words: Freirian pedagogy; feminist pedagogies; emancipatory traditions of the voice.

\section{INTRODUÇÃO}

Em trabalho anterior (AUTORA, 2017), parti da afirmação de Freire como feminista, e explorei ligações entre a proposta freiriana e feminista, para discutir interpelações entre

\footnotetext{
1 Professora Auxiliar na Faculdade de Psicologia e de Ciências da Educação da Universidade do Porto. Investigadora do CIIE- Centro de Investigação e Intervenção Educativas. Vice-Presidente da direção do Instituto Paulo Freire de Portugal. E-mail: eunice@fpce.up.pt

${ }^{2}$ Neste artigo, os originais em inglês foram objeto de tradução livre, da responsabilidade da autora.
} 
estas pedagogias que corporizam um pensamento emancipador. Reconheci aproximações, distanciamentos e ecos entre essas perspectivas. Neste artigo, retomo esse debate, acentuando diálogos e interpelações entre essas tradições teórico-metodológicas emancipatórias (ARNOT, 2006) e as suas pedagogias.

Entendendo o feminismo como movimento plural ligado a uma "estrutura básica de consciência" (LAMAS, 1995, p. 17), um movimento social internacional, possuidor de uma identidade teórica, autónoma e organizativa própria, como referem Carvalho, Vieira, Santos e Melo (2003), tomando por referência Álvarez, acentuo com Freire e Macedo (1998) as dimensões de autorreflexão e ação política feminista em busca da liberdade humana.

Estas são dimensões com que Freire afirma identificar-se, e que enraízam a sua visão de si como feminista. Esta asserção é contestada por algumas feministas, desde os anos 1970, em termos mais ou menos radicais. Realça-se que, apesar das críticas que lhe são apresentadas, Paulo Freire tem sido uma referência para muitas teóricas feministas, no que concerne à sua visão libertadora da pedagogia e à busca de humanização, embora com perspectivas distintas quanto aos significados destes conceitos. Dou relevo à predominância do gênero como situação limite de opressão, no caso do pensamento feminista e da prevalência da dominação de classe social, como situação-limite, na proposta freiriana. Certamente, o diálogo tem existido e, espera-se, continuará a existir. Procuro contribuir para esse diálogo, mostrando e construindo pontes entre essas tradições emancipatórias da voz (ARNOT, 2006).

\section{FEMINISMOS E FREIRE: DIÁLOGOS (IM)POSSÍVEIS?}

Enquanto teórica feminista, ativista e crítica social, bell hooks ${ }^{3}$ (1994), autora da obra fundadora "Teaching to transgress: education as the practice of freedom" foi uma aluna atenta de Freire. Note-se que o subtítulo desta sua obra recupera o título de Freire "Educação como prática de liberdade", para reafirmar o lugar da educação como prática (que pode ser) transgressiva e que abre lugar à aprendizagem da transgressão, como posicionamento político de rutura com o status quo. Face às críticas dirigidas a Freire, do uso

\footnotetext{
${ }^{3}$ O nome bell hooks deve ser mantido em minúsculas por reclamação da autora. Gloria Jean Watkins utilizando esse heterónimo em letra minúscula quer acentuar que o que tem importância é o conteúdo da obra e não a pessoa que a escreve.
} 
de uma linguagem sexista, hooks elogia a generosidade e abertura de espírito do professor, que coloca acima da de muitos intelectuais, incluindo as próprias feministas. hooks (1994, p. 49) reconhece que o "modelo da pedagogia crítica de Freire convida a uma interrogação crítica dessa falha no seu trabalho".

É já na Pedagogia da Esperança: um reencontro com a pedagogia do oprimido (FREIRE, 1994), que Freire reconhece a falta de sensibilidade de género, na "linguagem machista" usada nessa obra e assume a sua 'dívida' perante as mulheres. Curiosamente, na obra Learning to Question [Por uma pedagogia da pergunta], Freire reclama também das feministas críticas a aceitação dos contributos de homens que, como ele, recusam o machismo, e que, como ele, devem assumir o dever e o direito de agir na transformação social. Esta parece ser uma reação de Freire a um feminismo de 1a vaga muito focado ainda na afirmação da identidade das mulheres e em desocultar a sua posição subalterna (MACEDO; AMARAL, 2002), ou em afirmar a sua diferença (CORNELL, 1998) e, portanto, tendencialmente, com menos espaço para outras reivindicações e a abertura a outras vozes.

Mais recentemente, parecendo dar resposta ao repto de Freire, KONING (2006, p. 221) reconhece o seu contributo, partindo da reflexão de Morrow \& Torres, em 1998. Nessa linha, a autora acentua como "as 'teorias do sujeito pedagógico' que incluem 'a pedagogia crítica de Freire e a psicologia social crítica de Habermas' [...]" trazem à colação a 'opressão' das mulheres. Como ela afirma, e é sabido, esta categoria não foi tida em conta nem pela Teoria Crítica nem pela filosofia da conscientização, então focada, acrescentamos, nas relações de dominação-subordinação em termos de classe social. É de ter em conta, como a autora refere, baseando-se em Morrow e Torres, que Freire, tal como Habermas, tiveram como objeto a construção de perspetivas de cariz mais abrangente, sendo que em Freire, vem a emergir uma ideação sobre educação que tem em conta a dominação em termos de género, raça e etnia (KONING, 2006). Estas dimensões parecem, no entanto, surgir como complementares da dominação em termos de classe, em foco nessas perspetivas.

Numa linha distinta, Kathleen Weiler (2002), em Rereading Paulo Freire, tal como noutros trabalhos (WEILER, 1991, 1996), afirma que a adesão de muitas pesquisadoras feministas ao trabalho de Freire não resulta de um interesse pelo conteúdo das suas propostas, mas pelo estilo, da prosa freiriana, que descreve como apaixonado, bem como pelo seu compromisso com a justiça social e os direitos humanos (AUTORA, 2017). Segundo 
afirma, as pensadoras feministas apropriam também a retórica de Freire e o seu compromisso com a democracia e com a equidade, aportando-as a uma nova linguagem e visão de mundo. É também curioso pensar que a autora, nesta sua leitura, e de forma no mínimo controversa, parece reproduzir uma visão essencialista sobre a sensibilidade das mulheres, que parecem representadas como seres de emoção, que se deixam seduzir pelo estilo, sendo menos capazes de um pensamento racional crítico.

Vendo além da afirmação de identidade e de diferença, no pensamento feminista, Freire reconhece o contributo do feminismo como "processo de autorreflexão e ação política em prol da liberdade humana" (FREIRE; MACEDO, 1998, p. 14), movimento com que reconhece ter aprendido e que Ihe permitiu definir a sua obra como feminista. Paulo Freire e Donaldo Macedo afirmam ainda a sua recusa de um pensamento único em termos de classe e sexo (diria género), que não tem em conta a diversidade presente no sofrimento humano; bem como de "qualquer currículo que ignore o sexismo, o racismo, a exploração dos trabalhadores e outras formas de opressão, [que] suporta o status quo; [Este] argumento [...] abre espaço à reformulação e expansão do conceito de 'oprimido' para incorporar preocupações com a dimensão de género e a dimensão étnica, como formas de opressão" (AUTORA, 2017, p. 26).

Freire viria a abandonar a "linguagem sexista" no seu trabalho substituindo-a por uma linguagem-amiga-do-género, como ilustra a obra opus cit. e outros trabalhos (FREIRE, 1997, 2000a, 2000c, 2001; FAUNDEZ; FREIRE, 1998), em que o autor usa frequentemente expressões em que "homens e mulheres" se constituem como seres aprendentes e transformadores, em que a sociedade e intelectualidade se renovam a partir "do novo homem, da nova mulher", entre outras formulações tendencialmente inclusivas.

Surge ainda na sua ampla e significativa produção teórico-experiencial, a obra Professora Sim, Tia Não: cartas a quem ousa ensinar, na qual Freire (1993) assume reivindicações caras ao movimento feminista de reconhecimento da profissionalidade das mulheres-professoras. Explicitamente, o autor resiste à ideia de maternage associada ao exercício da profissão docente, como prolongamento do ato de cuidar da família para a escola, que tantas vezes surgiu como justificativa da inserção das mulheres como professoras. Ideia essa presente no uso da palavra 'tia'. Reivindicando dignidade profissional para as mulheres professoras, como cidadãs de direitos, alega: 
Ensinar é profissão que envolve certa tarefa, certa militância, certa especificidade no seu cumprimento (...) implica assumir uma profissão. (...) Recusar a identificação da professora com a da tia (...) se deve sobretudo a duas razões principais. De um lado, evitar uma compreensão distorcida da tarefa profissional da professora, de outro, desocultar a sombra ideológica repousando, manhosamente na intimidade da falsa identificação. Identificar professora com tia, o que foi e vem sendo ainda enfatizado (...) é como proclamar que professoras, como boas tias, não devem brigar, não devem rebelar-se, não devem fazer greve. (FREIRE, 1993, p. 11-12).

Esta nova linguagem-amiga-de-género e postura de Freire, que anuncia uma visão de mundo com uma preocupação mais inclusiva, rompe com a universalização do 'oprimido', como aparente neutro masculino (LISTER, 1997), bem como com um abuso 'naturalizado' da linguagem, corrente na sua época. De forma preocupante, este abuso prevalece hoje, ainda, e em muitos contextos, apesar dos contributos feministas e de Freire (AUTORA, 2017).

\section{UMA POLÍTICA NA EDUCAÇÃO PARA ALÉM DO TEMPO E DO LUGAR}

Como já referi, o trabalho de Freire esteve sob o olhar de Kathleen Weiler cujas muitas críticas incluem o não endereçamento das questões de género, uma visão patriarcal e uma posição de privilégio masculino, e uma tendência de generalização e universalismo com consequências negativas para as lutas sociais. No entanto, no que concerne ao pensamento e pedagogia de Freire, Weiler (2004) reconhece que estes se desenvolveram em circunstâncias particulares, em termos históricos e políticos, sob vigência do neocolonialismo e do imperialismo sendo crucial lê-los à luz da sua época.

Num diálogo que aparentemente não existiu, curiosamente, Freire (1981), dava já relevo aos desafios trazidos pela dimensão epocal, descrevendo como unidade epocal o "conjunto de ideias, de concepções de esperanças, dúvidas, valôres, desafios em interacção dialéctica com seus contrários, buscando plenitude" (FREIRE, 1981, p. 109). Podemos completar esta ideia, também nas suas palavras, na afirmação "[...] o momento de uma geração faz parte, porque histórico, revela marcas antigas que envolvem compreensões da realidade, interesses de grupos, de classes, preconceitos, gestação de ideologias que se vêm perpetuando em contradição com aspectos mais modernos" (FREIRE, 2000a, p. 54). Na mesma linha de orientação, também KONING (2006, p. 85), inspirando-se no pensamento de 
Rosi Braidotti enuncia que é preciso uma "política de tempo e de lugar' [...] que define sempre a experiência".

Havendo, no trabalho de Freire uma forte dimensão de intemporalidade, que se expressa no facto de o seu trabalho continuar a ser uma referência ao nível mundial, como um dos maiores pedagogos dos nossos tempos, reconhecemos que o seu contributo, como outros contributos que partem da realidade para a reflexão e dela regressam para a reconstrução do pensamento e o anúncio de uma nova realidade possível, é fortemente influenciado pelos seus contextos de vida e do seu diálogo com as pessoas (ROMÃO, J.; ROMÃO, N., no prelo, SCOCUGLIA, no prelo, AUTORES, 2018).

Por sua vez, bell hooks (1994) desenvolve uma pedagogia feminista engajada com as pessoas e com os seus contextos de vida, uma abordagem com relevância para contextos multiculturais pautados pela diversidade, com clara inspiração em Freire e, particularmente, na Pedagogia da Esperança (FREIRE, 1994). Centra-se na busca e reinvenção feminista da educação como prática da liberdade e na enunciação da politicidade da educação, com preocupações de género. Com essas preocupações, reafirma que tal busca "implica o questionamento de um sistema baseado na 'educação bancária' e o apelo à participação ativa das e dos estudantes na construção do saber, através do desenvolvimento da consciência e da reflexão transformadora" (AUTORA, 2017).

Muito se tem dito sobre a educação bancária, expressão cunhada por Freire que acentua que, pela sua imputação de passividade e ignorância às e aos educandos, este depósito de conhecimento acabado, nas e nos educandos, impede a descoberta dos seus mundos vivenciais, correspondendo à "inculcação de normas e à normalização desses mundos face a um modelo socioideológico e histórico-cultural assente na opressão e na negação do 'outro' (AUTORA, 2017, p. 33). Assente em padrões de cientificidade das classes dominantes, serve à transmissão dos mitos que estas usam para se legitimar, conduzindo à interiorização como seres menores e à crença na superioridade dos opressores; um processo que facilita a manutenção da estratificação social (AUTORA et al., 2013). Pode assim afirmarse que a educação bancária se constitui como modo de opressão pois é corporizada num ato de violência, associado a um diferencial de poder, sendo que

(...) as pessoas/grupos em posição de poder são formatadas numa consciência possessiva de dominação e localizam os oprimidos como coisas, 'seres duais' conformados 'como violentados, numa situação objectiva de 
opressão'. Essa relação de poder desigual, de que resulta uma postura de fatalismo e de assunção da menoridade por parte das pessoas oprimidas, é suportada na imposição de uma 'cultura do silêncio', cujas vozes não são ouvidas pelos membros dominantes da sociedade (Freire, 1999: 42). (AUTORA, 2017, p. 41).

É neste enquadramento que a filósofa feminista e cientista política norte americana Iris Young descreve também a opressão como corporizada

\begin{abstract}
em processos institucionais sistemáticos [como os de educação bancária] que impedem que certas pessoas aprendam e usem competências satisfatórias e expansivas em espaços sociais reconhecidos, ou processos sociais institucionalizados [como as relações educativas, na escola] que inibem as pessoas na sua capacidade para interagir e comunicar com outras ou para expressar sentimentos e perspectivas na vida social em contextos em que outras as possam ouvir. (YOUNG, 1990, p. 38).
\end{abstract}

Ao referir-se à opressão como exercício de poder com múltiplas faces, e com possibilidade de cruzamentos múltiplos, esta autora afasta-se do binómio opressor-oprimido para acentuar o efeito de práticas liberais e 'humanas' como a educação, em que a opressão é reproduzida, por vezes, de forma não consciente. Esse é o caso de pessoas que, não se assumindo como "agentes de opressão", mas exercendo um poder instituído, afetam as vidas e o trabalho do quotidiano de pessoas em posições de subalternidade. É interessante referir aqui que, também com estes argumentos, Iris Young se distancia "do pensamento crítico mais convencional, que tende a universalizar a experiência de opressão de grupos específicos, em termos de classe social, no interior do binómio burguesia-operariado." (AUTORA, 2017, p. 46).

PEDAGOGIA FREIRIANA E PEDAGOGIAS FEMINISTAS: PROVOCANDO UM ENCONTRO POSSÍVEL

Josephine C. Donovan (1989) estabelecia já analogias entre a proposta freiriana de uma educação libertadora e as práticas feministas de tomada de consciência, 'irremediavelmente' associadas à pedagogia, numa base marxista de construção de identidade de grupo e de solidariedade. Outras articulações são também possíveis.

Maria de Lourdes Pintasilgo (1998) atribui a Freire características que podemos associar a um pensamento feminista. Acentua, 
Paulo Freire foi um dos primeiros pensadores a dar voz à complexidade princípio orientador da auto-organização dos sistemas - enquanto raiz da relação teoria/ prática. E começou o trabalho sobre a complexidade ao nível mais alto, onde ela é irredutível a elementos simplistas - ao nível do ser humano. A sua perspectiva da conscientização parte do princípio de que cada pessoa traz em si o universo inteiro (...). Esse reconhecimento vai, por isso, até ao ponto de postular que o processo de conquista da liberdade individual é o detonador do processo de libertação da sociedade (PINTASILGO, 1998, p.3).

A ideação da educação como ato político libertador, na Pedagogia do Oprimido, e como princípio transversal da filosofia política da educação de Freire, foca e potencia o movimento desde uma consciência real, a uma consciência transitiva e a uma consciência crítica, por meio da conscientização, permitindo "[...] à pessoa oprimida a transição da desumanização à humanização, pela tomada de consciência das suas "situações-limite" de opressão e do potencial transformador da própria história, através da voz" (AUTORA, 2017, p. 44).

A ideação de Freire, numa linha da teoria crítica, corporizada numa pedagogia libertadora, anuncia que "a leitura da palavra" permite a "leitura da palavramundo" (FREIRE, 2000a, 2001), para transformar esse mundo. Evidencia-se a articulação entre discurso/voz "palavra" - e a ordem social que esta expressa e pode transformar - "mundo". Numa linha de pensamento feminista, assumo a voz como conceito sociológico que expressa a história, experiência, saberes, visões e expectativas de mundo, de pessoas e grupos concretos em situações de vida concretas (AUTORA, 2018) constituindo um elemento crucial da consciência crítica. A voz, em Freire, corporiza processos dialógicos coletivos acerca das realidades de vida das pessoas, sendo a partir das suas experiências que as pessoas podem expressar-se, recuperando a posição de sujeitos para, conjuntamente, modificarem as condições de opressão que percebem partilhar entre si.

A questão da palavramundo, no cruzamento entre experiência individual e construção coletiva, tal como proposto por Freire, recebeu oposição do pensamento póscolonial e pós-estruturalista, no qual se inserem algumas linhas do pensamento feminista já referidas. Estas argumentam que voz e discurso passam a ser fragmentados, uma ideação que corresponde a uma desconstrução de metanarrativas presentes em conceitos como 'classe social', 'mulher', 'jovem' que tendem a homogeneizar uma experiência de grupo que 
considero necessariamente distinta e heterogénea, embora com elementos partilhados, dada a ocupação por diferentes indivíduos de localizações estruturais de poder distintas e em diferentes combinações, como sugere Young (1990). Há, pois, que reconhecer que

se a ênfase nas questões da redistribuição legitimou a centralidade da dimensão de classe social; o alheamento das questões de reconhecimento e da diferença, legitimou, por exemplo, a invisibilização do género, crucial para o movimento feminista. (AUTORA, 2017, p. 48).

Como tenho também vindo a referir a asserção de uma voz unânime dos "oprimidos" e do próprio conceito de opressão tem vindo também a ser desconstruídas por contributos oriundos, por exemplo, do campo da filosofia, como é o caso de Iris Young, que referi acima, cuja ideação permite criticar o potencial enquadramento dessas visões numa epistemologia objetivista, onde se poderiam detetar princípios de verdade universal. Apesar de mais estas críticas, e talvez pelas muitas reflexões que impulsiona, a visão freiriana de uma pedagogia libertadora tem, em alguns casos, suportado a concetualização feminista da libertação das mulheres e de outros grupos em posição de vulnerabilidade, sendo que, noutros casos, pode ter sido inspirada por ela.

No primeiro caso, da influência freiriana, inclui-se bell hooks que, apesar de unida a Weiler, e a outras feministas, na crítica à falta de sensibilidade de género na proposta de Freire, se reconhece identificada com o seu pensamento, particularmente no que concerne ao questionamento dos pressupostos políticos nos Estados Unidos, sociedade em que estava inserida, e onde se afirmava uma política de dominação, racismo, sexismo, exploração de classe, e colonização interna (hooks, 1994). Tal como refere a autora, Freire conta-se entre os pensadores que the proporcionam uma linguagem de resistência revolucionária, que incorpora um pensamento mais crítico e transformador. Não é, pois de estranhar, a acentuação por hooks da convergência entre a pedagogia feminista e a obra de Freire. Assim, hooks constrói o seu "pensamento acerca da arte de ensinar" (hooks, 1994 apud AUTORA, 2017, p. 35) na interpelação mútua entre "a proposta freiriana e a 'pedagogia viva' de muitas e alguns docentes negros investidos de uma missão libertadora contra "o racismo e a supremacia branca" (ibidem). 
Também a pedagoga freiriana e feminista Marijke de Koning (2006, p. 80), com implicação e ação na formação e conscientização de mulheres, assume a influência da pedagogia freiriana, de modo transversal, no seu trabalho educativo, referindo que esta é "[...] como a partitura principal em que o tema é retomado em diferentes trechos, às vezes apenas por notas que já se confundem com outras partituras" (KONING, 2006, p. 35), uma afirmação que nos reporta a uma visão do feminismo de influência freiriana como "estrutura básica de consciência" (LAMAS, 1995, p. 17), um guião orientador da prática e da reflexão sobre ela, com potencial transformador.

Na sua formulação da conscientização como "processo que leva o indivíduo a passar de um estado de consciência 'ingénua' a um estado cada vez mais avançado de consciência crítica activa", Koning (2006, p. 47) aproxima a ideação de Freire e de Maria de Lourdes Pintasilgo ${ }^{4}$, acentuando o foco na mútua interpelação entre estrutura e sujeito, que situa mulheres e homens como "sujeitos e atores da própria história" (FREIRE, 1997, p. 40). Koning (2006) acentua essa proximidade entre Pintasilgo e Freire, no pressuposto de que a conscientização coloca às pessoas desafios que emergem da busca de objectivação da sua situação, pela tomada de palavra, a qual suporta e estimula a sua consciência de sujeito, de tal modo que são os constrangimentos e circunstâncias sociais que levam as pessoas ao movimento de uma consciência ingénua a uma consciência crítica ativa. Na mesma linha, Freire (1997) refere também que mulheres e homens se relacionam com o mundo num movimento constante de busca com as outras pessoas, o que implica fazer história, e ser feito por ela, produzir e ser produzido pela cultura, assumindo e politizando a presença no mundo.

Assumindo também a relevância da tomada da palavra, como elemento da práxis, bem na linha freiriana, na mesma obra, Marijke de Koning acentua o poder transformador da palavra-ação. Nessa medida reflete sobre o trabalho de formação a partir da experiência, que objetiva a mudança social. Complexificando a proposta de Freire, acentua ainda a multiplicidade de percursos individuais e coletivos associados à aprendizagem com conscientização. Afirma, "o saber narrativo que informa os momentos hermenêutico e

\footnotetext{
${ }^{4}$ Maria de Lourdes Pintasilgo foi engenheira química, dirigente eclesial e política portuguesa, tendo sido a única mulher que assumiu o cargo de primeira-ministra em Portugal, como chefe do V Governo Constitucional, entre julho de 1979 e janeiro de 1980. Foi responsável pela ideação de uma ética do cuidar, de grande relevância para o pensamento feminista e para um movimento social transformador.
} 
crítico analítico do processo andragógico exige alternadamente uma implicação subjetiva e um distanciamento objectivo" (KONING, 2006, p. 70).

Freire acentuava já, na Pedagogia do Oprimido, que a praxis educativa dialógica, inerente à conscientização, "permite o desvio de uma cultura de silêncio' para uma consciência política, adquirida através do desenvolvimento de um pensamento crítico, e traduzida na capacidade de nomear o mundo." (AUTORA, 2017, p. 32). É interessante referir também que, apesar das muitas críticas a Freire, Weiler (2004) estabelece articulações positivas entre a pedagogia feminista e a pedagogia freiriana, acentuando o foco de ambas numa ideação da transformação social, associada a preocupações com a opressão, a tomada de consciência e a mudança histórica. Parecendo acentuar um desvio paradigmático do seu pensamento crítico face a Freire, Weiler (2004) enuncia a articulação entre a tradição emancipatória da voz proposta por Freire e a proposta pela tradição feminista. Esta autora parece rendida a Freire, como outras feministas que anteriormente criticou, concordando com este pedagogo crítico, em termos dos conteúdos da sua proposta, no que concerne à sua visão do feminismo como fortemente relacionado com o processo de autorreflexão e de ação política em favor da liberdade humana (FREIRE; MACEDO, 1998), que já referi.

Para além disso, Weiler (2004) enuncia ainda que ambas as perspetivas - feminista e freiriana - situam a opressão nas condições materiais da vida das pessoas e buscam o desenvolvimento de uma consciência crítica que diríamos capaz de denunciar discursos e modos de vida dominantes e anunciar novos mundos possíveis. Um outro aspeto de articulação, reafirmado pela autora, é o comprometimento com a justiça de ambas as pedagogias e a ideação de um mundo melhor com potencial libertador, sendo os seres humanos vistos como sujeitos e atores/autores da história (WEILER, 2004). Esta formulação provoca-nos duas notas. A primeira é que, curiosamente, Freire formula argumentos similares, que referi acima, para se afirmar como feminista, a segunda nota é que os significados atribuídos a estes conceitos, bem como o seu foco podem ser distintos, como também já acentuei.

Com relevo para este argumento, conforme AUTORA (2017, p. 47) a socióloga da educação Madeleine Arnot (2006), "inclui a tradição feminista e a tradição crítica - na qual se insere Paulo Freire - como movimentos paralelos (...) de uma 'tradição emancipatória da voz'". Esta é vista como fundamental para um trabalho educativo que se distancie das 
políticas e visões neoliberais da voz, da tradição neoliberal, que situam as e os estudantes como clientes. Arnot estabelece estas linhas da tradição emancipatória como

abordagens teóricas e metodológicas que lutam contra o silenciamento das pessoas e grupos oprimidos, e que assumem a centralidade da voz como modo de legitimação e ampliação da cidadania (...) de grupos minoritários ou desfavorecidos. (AUTORA, 2017, p. 47)

Distinguindo-se pelo seu foco, a tradição feminista parte do género para abranger outras condições, a segunda, a crítica, parte de 'classe social', como conceito hoje também reconfigurado, em torno da fragmentação das e dos sujeitos da cidadania, e de uma reconceptualização de quem se considera oprimido.

Promovendo diálogo com as teóricas e pedagogas feministas, Freire e Macedo sugerem-nos a necessidade de criar uma prática pedagógica cuja estrutura obrigue os homens a confrontar-se com as suas próprias posições opressivas. Isto implica, como continuam a referir, que as feministas compreendam também "os diferentes níveis de opressão masculina"5(FREIRE; MACEDO, 1998, p. 208). Assim sendo, admite que mulheres e homens que ocupam relações de poder desigual de oprimidas e opressores, ao desconstruírem as "suas diferentes posições nas estruturas opressivas" poderão em conjunto desenvolver estratégias eficazes na sua libertação das suas situações-limite de opressão (FREIRE; MACEDO, 1998, p. 208). Ora a premência desta participação conjunta na construção democrática é também acentuada por algumas linhas do movimento feminista, como movimento plural pela libertação ligado a uma "estrutura básica de consciência" (LAMAS, 1995, p. 17) informada pelo gênero, em que se acentua a interseccionalidade ${ }^{6}$ com outras dimensões das nossas vidas humanas e do nosso ser e estar no mundo, como sujeitos, em processo. Por exemplo, Amaral (2004) anuncia a necessidade de envolver mulheres e homens no movimento pela libertação.

É face a estes argumentos que Freire reconhece à prática pedagógica feminista capacidade para intervir e alterar essas relações, baseando-se também na premissa, muito

\footnotetext{
${ }^{5}$ Refira-se que este foco tem sido evidenciado por estudos feministas centrados em preocupações com a heteronormatividade e as relações de dominação-subordinação associadas à construção das masculinidades e femininidades, por exemplo, ou que acentuam e defendem a diversidade afetivo sexual. (AUTORA, 2012, 2015; SANTOS; ARAÚJO, 2007)

${ }^{6}$ Para uma exploração cuidada da interseccionalidade, consulte-se Conceição Nogueira, 2017
} 
presente no seu trabalho praxiológico de que a libertação das pessoas opressoras está nas mãos das pessoas oprimidas que, ao libertar-se, arrastam nesse processo, outras pessoas.

Por sua vez, outras abordagens admitem que a pedagogia feminista se baseia nas teorias críticas acerca do ensino e da aprendizagem, como proposto por Freire (ex, Dawn, 1992), afirmando que essa influência na pedagogia feminista estará no amor de Freire pelo ensino (como relação educativa, num vaivém entre ensinar e aprender), pelo conhecimento (como processo em construção), por cada aprendente (como ser único em busca de ser mais), e pela relação docente/estudante como seres implicados na transformação do seu mundo, autores e autoras da sua história.

Cabe aqui lembrar o relevo atribuído por Freire à amorosidade, que vemos como princípio transversal ao seu trabalho. Por exemplo, na obra $A$ importância do ato de ler em três artigos que se completam (FREIRE, 2000b), como referem Autora et al. (2013, p. 136) a amorosidade é descrita como "ato de abertura à aceitação e compreensão" da outra pessoa e do mundo, numa valorização dessa relação por si e não apenas como condição para a aprendizagem.

Entre outras condições da relação humana de construção de saber (mais) e ser (mais), é no quadro dessa amorosidade que se dá relevo também à construção de respeito mútuo, à valorização das diferenças e à co-laboração para atingir objetivos partilhados. Abre-se espaço à aprendizagem participativa que valida e valoriza a experiência e saberes individuais e que encoraja o ativismo social e o desenvolvimento de pensamento crítico. Emerge, então, como atinente a consciência e abertura à diversidade para a relação entre pessoas e com o mundo como condição que enriquece essa experiência; bem como o papel crucial da dimensão relacional na relação pedagógica e mais além.

\section{UMA LEITURA DA PEDADOGIA FEMINISTA COM PEGADAS DE FREIRE: MOSTRANDO E} ENCONTRANDO PONTES

A pedagogia feminista, que dá corpo e contribui para o movimento feminista, é mais associada por Emily Henderson (2016) a um posicionamento gnosiológico do que a um método prescritivo. Acrescento como particularidade desta pedagogia a intenção e ação política para o reforço de uma agenda de género na educação e, de forma mais ampla, no contexto político e social. Como diz Laura Fonseca (2007, p. 56), uma nova agenda de 
género, que introduza "novos dados e configurações discursivas" (ver também NÓBREGA, 2005).

Tal como face a outros processos complexos que envolvem a ação humana, há grande diversidade de formas de descrever os princípios orientadores da pedagogia feminista, como experiência ontológica e gnosiológica, não podendo reduzi-la a uma listagem fixista. Trata-se, pois, de uma abordagem fragmentada, no sentido de multi direcionada e com várias interpretações, um processo situado e em construção, que se enraíza e cresce com as diferentes pessoas e grupos que a ela recorrem na busca de justiça e transformação social libertadora. Ao constituir-se como particularidade, no exercício por e com pessoas concretas em contextos concretos assenta e expande uma base sólida.

Os princípios, abaixo referidos, constituem sistematizações possíveis, um pano de fundo da estrutura básica de consciência feminista. Assim, partilho, neste ponto, duas perspetivas com articulações diversas, em que reconheço a pegada de Freire, com que vos desafio também a dialogar.

Lynne Webb, Kandi Walker e Tamara Bollis (2004) estabelecem seis princípios da pedagogia feminista:

1 - reformulação da relação entre educadores e educadoras, de um lado, e educandos e educandas, de outro, com afastamento de um ensino transmissivo e a passagem a uma educação participada.

2 - empoderamento, finalidade primeira, que assenta na não neutralidade da educação, implicando educar para a não conformação, ou seja, para a liberdade e a resistência face ao instituído

3 -construção de comunidade, que diz respeito ao desenvolvimento de processos de cooperação na e para além da sala de aula, com base na valorização de todas as pessoas e no desenvolvimento de um sentido de confiança para participar e agir.

4 - valorização da voz, com um ponto de partida de género, resultando na diluição da hierarquia entre educador ou educadora e educando ou educanda, com promoção de maior equidade.

5 - respeito pela diversidade da experiência pessoal, como fonte de análise, produção teórica, ativismo e pesquisa, ... 
6 - desafio às noções tradicionais de pedagogia, que resulta dos anteriores, ligado à asserção da não neutralidade ontológica da pedagogia, implicando a não reprodução e reforço da construção social de género, em torno de binómios como socialização/ autonomia, público/ privado, masculino/ feminino.

Por sua vez, Emily Henderson (2016) sistematiza três princípios centrais na pedagogia feminista, que vejo como aglomeradores dos princípios da proposta anterior:

1 - resistência à hierarquia entre as e os educadores, de um lado, e as e os educandos, de outro, o que implica a participação das e dos últimos na construção de conhecimento e na definição do próprio processo de aprendizagem;

2 - tomada da experiência como recurso, para além dos métodos tradicionais, o que permite documentar e discutir experiências até aí alienadas, potenciadora da identificação de situações reais de opressão como base para a aprendizagem transformadora

3 - aprendizagem transformadora, que vai além da aquisição de novos conhecimentos para permitir pensar novos sentidos, incluindo a reinterpretação e revalidação crítica da experiência.

A pegada de Freire pode ser, claramente, identificada nos princípios estabelecidos em qualquer destas abordagens, sendo que as articulações e justificações estabelecidas entre os princípios surgem de forma diversificada. A reformulação da relação entre educadores ou educadoras e educandos ou educandas é um dos princípios centrais da pedagogia do oprimido, e muito clara na passagem da educação bancária à educação libertadora, o que implica uma nova visão sobre quem possui saber e qual o saber válido, ou seja reconhecer tanto os saberes e cultura das e dos aprendentes como o seu papel crucial como atores e atoras e autores e autoras na formulação do saber (AUTORA, 2017).

Dita de outra forma, a questão do empoderamento, cara às perspetivas feministas, é também crucial na praxis freiriana, que ao desvelar e recusar o papel da educação na reprodução do status quo, e ao recorrer à conscientização através da dialogicidade, se funda na ética, no respeito à dignidade e à autonomia das e dos educandos, conduzindo, assim, à sua construção como sujeitos sócio históricos e culturais inseridos num grupo (FREIRE, 1997). Há que fazer uma nota relativa ao foco das pedagogias feministas no sujeito 
individual e coletivo, enquanto na perspetiva freiriana, a emersão do sujeito individual se dirige mais ao empoderamento do grupo (AUTORA, 2020).

Relacionando-se com o que atrás foi dito, o princípio da construção da comunidade é de particular relevo na pedagogia freiriana, sendo claramente corporizado nos "círculos de cultura", como modo de trabalho educativo que assenta e estimula a construção coletiva de sentidos a partir do confronto dialógico das realidades individuais. É nessa articulação que Freire alerta acerca da necessidade de "uma postura vigilante contra todas as práticas de desumanização" (ibidem:12), anunciando "a solidariedade enquanto compromisso histórico entre homens e mulheres, como uma das formas de luta capazes de promover e instaurar 'a ética universal do ser humano'" (ibidem:13).

Quanto ao conceito de voz, enquanto experiência, história, cultura, expectativas e visões de mundo (AUTORA, 2018), o ponto de partida é bem distinto, talvez o mais distinto, nestas duas tradições teórico-metodológicas emancipatórias da voz (ARNOT, 2006), embora relevante em ambas. É assumido o ponto de partida de género das pedagogias feministas, à luz da teoria feminista, e o de classe social, na pedagogia freiriana, à luz das teorias críticas. A dimensão cultural e a valorização da voz, como recurso e efeito de conscientização e ação transformadora evidenciam-se em ambas as abordagens. Freire denuncia o silenciamento das vozes na educação e enuncia a necessidade de ter em conta "a cultura dos oprimidos, sua linguagem, sua forma eficiente de fazer contas, seu saber fragmentário do mundo de onde afinal transitariam até ao saber mais sistematizado, que cabe à escola trabalhar" (FREIRE, 1974, p. 35).

Anuncia-se com Freire, e tal como nas visões pedagógicas feministas, a valorização da diversidade, inerente à alfabetização - como projeto e ação política - centrada na deteção de temas geradores e na exploração de palavras geradoras, atinentes à experiência específica das e dos alfabetizandos, e ao seu universo vocabular. Tal processo, raiz e caule da instauração da consciência, através da dialogicidade, confere a cada pessoa oprimida lugar para se expressar, se apropriar da sua história e criar cultura, pela objectivação do mundo, como acentua Freire (1981). Também no que concerne à noção de diversidade, na sua relação com a voz, parece importante acentuar que, enquanto na teoria freiriana o foco parece estar no sujeito como membro de um grupo tendencialmente homogéneo, porque partilha circunstâncias de classe similares, na pedagogia feminista, reconhecendo-se a 
partilha de determinadas condições estruturais, como o género, enfatiza-se também a intersecção de outras dimensões, como condições que expandem a diversidade enquanto heterogeneidade intragrupal (YOUNG, 1997).

Quanto ao desafio à pedagogia convencional, parece já clarificado no parágrafo anterior, no que concerne ao lugar das e dos sujeitos. No entanto acentuo como também marcante nesse desafio o questionamento ao status quo e ao próprio conhecimento, pois, ambas as pedagogias reconhecem a existência de diversas formas de opressão, que obriga a essa ação para a transformação social libertadora (CRABTREE; SAPP; LICONA, 2009). Isso é marcante na proposta filosófica, política e pedagógica de Freire pelo seu caráter transformador, humanizador, problematizador e libertador, que vai ao encontro das reivindicações das teóricas feministas. Tal como ele argumenta, a educação não é neutra, mas (in)formada ideológica, histórica e culturalmente, sendo que, como ação cultural de intervenção no mundo, pode fazer a diferença (FREIRE, 1997). Assim anuncia,

Entre as potencialidades e limites da educação nasce um pensamento pedagógico que leva o educador [ou educadora] a se engajar social e politicamente, a perceber as possibilidades de acção cultural e social na luta pela transformação das estruturas opressoras para uma sociedade de iguais e o papel da educação - conscientização - nesse processo de mudança" (FREIRE, 1997, p. 10).

\section{CONSIDERAÇÕES FINAIS ${ }^{7}$}

Como vos desafiei a pensar, assumindo pontos de partida distintos e diferentes movimentos de expansão, há um diálogo possível entre a pedagogia crítica libertadora, da praxis freiriana, e as pedagogias feministas pois tanto a pedagogia libertadora, na ideação de Freire, como a pedagogia feminista partem da preocupação e desocultação de relações de poder desigual entre grupos e entre pessoas, acentuando como a tomada de consciência culmina na ação transformadora, corporizando a conscientização.

\footnotetext{
${ }^{7}$ No Projeto EduTransfer - Aprender através de diversos contextos educativos: Transferibilidade de práticas promissoras no quadro do Horizonte 2020, financiado pela Fundação para a Ciência e a Tecnologia (ref. a PTDC/CED-EDG/29886/2017) e atualmente em decurso, de que sou co coordenadora, orientamos o trabalho de pesquisa, a formação de docentes e jovens, a implementação da aprendizagem baseada na resolução de problemas (e a reflexão sobre), com base na dialogicidade, num cruzamento entre pedagogia freiriana e pedagogia feminista, no sentido da conscientização e autonomização de pesquisadoras, docentes e jovens como grupos sociais e seres individuais em processo, autoras e autores da sua história educativa partilhada, e mediatizados pelo mundo.
} 
Pode dizer-se que ambas as propostas - freiriana e feminista - advogam a necessidade de autoquestionamento e de encorajamento das e dos aprendentes para que saiam de um papel passivo de recetáculos da aprendizagem - como situações-limite que oprimem -, para passarem a atores e atoras, autores e autoras da sua construção. Nessa medida, também ambas as propostas propõem o distanciamento e rutura com a hierarquização entre saberes, enraizada na divisão entre cultura escolar legítima e culturas populares, divisão que, por sua vez, constitui um dos pilares da hierarquização entre educadores/as e educandos/as, que é também necessário ultrapassar.

Nesse movimento de rutura múltipla, ambas as propostas fazem recurso a estratégias de empoderamento das e dos educandos no duplo papel de ensinantes e aprendentes. Isto quer dizer que cada participante na relação pedagógica relacional contribui com a sua cultura e voz para a construção de conhecimento e dialoga com outras culturas e vozes na apropriação de conhecimento novo. Promove-se a articulação entre conhecimento e poder, conducente à ação transformadora, referida acima. Trata-se, em ambos os casos, de pedagogias comprometidas com a justiça social, os direitos humanos e uma visão de possibilidade de construção de um mundo melhor, pela libertação, como acentuei noutros trabalhos. É no quadro dessa rutura múltipla, produzida como resistência, que ganha atualidade a enunciação de Freire, clamando e reclamando ação em busca de justiça e como vocação ética,

O discurso da impossibilidade de mudar o mundo é o discurso de quem, por diferentes razões, aceitou a acomodação, inclusive por lucrar com ela. A acomodação é a expressão da desistência da luta pela mudança. Falta a quem se acomoda, ou em quem se acomoda e fraqueja, a capacidade de resistir. É mais fácil a quem deixou de resistir ou a quem sequer foi possível em algum tempo resistir aconchegar-se na mornidão da impossibilidade do que assumir a briga permanente e quase sempre desigual em favor da justiça e da ética (FREIRE, 2000a, p. 40-41).

\section{REFERÊNCIAS}

MACEDO, E., VASCONCELOS, L., EVANS, M., LACERDA, M., \& VAZ PINTO, M. Revisitando Paulo Freire: Sentidos na educação. Brasília: Liber Livro, 2013.

MACEDO, E. (Re)Constructing femininities and masculinities: Northern Portuguese students speak about their lives, desires and dreams. Educação, Sociedade \& Culturas, 35, 2012, p. 67-88. Disponível em: http://www.fpce.up.pt/ciie/revistaesc/ESC35/ESC35_Macedo.pdf 
MACEDO, E. Violência e violências sobre as mulheres: Auscultando lugares para uma democracia 'outra' mais autêntica. In: BRABO, T. (Ed.), Mulheres, gênero e violência. Marília: Oficina Universitária \& São Paulo: Cultura Acadêmica, 2015, p. 15-35.

MACEDO, E. Paulo Freire, um pensador feminista? (Re)articulando conceitos e debates. In: MACEDO, E. (Coord.) Ecos de Freire e o pensamento feminista: Diálogos e esclarecimentos. Porto. LivPsic, IPFP, CRPF \& CIIE, 2017, p. 23-58.

MACEDO, E., \& CARVALHO, A. Intertextualidade em Freire: Pedagogia da Esperança ao encontro da Pedagogia do Oprimido, continuidades e pensamento novo. Educação Em Perspectiva, v. 9, n.3, 2018, p. 564-575. Disponível em: https://doi.org/10.22294/eduper/ppge/ufv.v9i3.1110

MACEDO, E. Cativar para ser: Interdependência, voz e autoria na educação com aprendizagem pela conversa. In: SILVA, M. e BRABO, T. (Orgs). Direitos humanos, diversidade, gênero e sexualidade: reflexões, diagnósticos e intervenções na pesquisa em educação. Marília: Oficina Universitária \& São Paulo: Cultura Acadêmica, 2020, p. 29-58.

MACEDO, E. Vozes jovens entre experiência e desejo: cidadania educacional e outras construções. Porto: Afrontamento, 2018.AMARAL, M.L. Um povo de homens e de mulheres em país de constituição débil. ex-aequo. v. 10, 2004. p. 17-28.

ARNOT, M. Gender voices in the classroom. In: SKELTON, C.; FRANCIS, B.; SMULYAN, L. (Orgs.), The Sage handbook of gender and education. London: Sage, 2006, p. 407-421.

CARVALHO, C. et al. Feminismo, conceito polémico: perspectiva histórica. In: MARQUES, C. et al. Um olhar sobre os feminismos: pensar a democracia no mundo da vida. Porto: UMAR, 2003.

CORNELL, D. At the heart of freedom: feminism, sex, and equality. Princeton, N.J.: Princeton University Press, 1998.

CRABTREE, D.; SAPP, A.; LICONA, C. (Eds.) Feminist pedagogy: looking back to move forward. Baltimore: The Johns Hopkins University Press, 2009.

DONOVAN, J. Radical feminist criticism. In: DONOVAN J. (Ed.), Feminist literary criticism: explorations in theory. Lexington: The University Press of Kentucky, 1989, pp. ix-xxi.

FAUNDEZ, A., \& FREIRE, P. Por uma pedagogia da pergunta. (4. a ed.). Rio de Janeiro: Ed. Paz e Terra, 1998.

FONSECA, L. Contornos da escolarização das raparigas em Portugal: olhar sócio-histórico para ressignificar as mudanças educacionais e uma nova agenda de género em educação. exaequo. v. 15, 2007. p. 69-87. 
FREIRE, P. Uma educação para a liberdade. Textos marginais 8. Porto: Ed. António Abreu, 1974.

FREIRE, P. Pedagogia do oprimido. Rio de Janeiro: Ed. Paz e Terra, 1981.

FREIRE, P. Professora sim, tia não: cartas a quem ousa ensinar. S. Paulo: Olho d'Água, 1993.

FREIRE, P. Pedagogia da esperança: um reencontro com a Pedagogia do Oprimido. S. Paulo: Ed. Paz e Terra, 1994.

FREIRE, P. Pedagogia da autonomia: saberes necessários à prática educativa. Rio de Janeiro: Ed. Paz e Terra, 1997.

FREIRE, P. Pedagogia da indignação: cartas pedagógicas e outros escritos. S. Paulo: UNESP (FEU), 2000a.

FREIRE, P. A importância do ato de ler: em três artigos que se completam (39. a Ed.). S. Paulo: Cortez Editora, 2000b.

FREIRE, P. Pedagogia da esperança: um reencontro com a pedagogia do oprimido (7.a Ed.). Rio de Janeiro: Paz e Terra, 2000c.

FREIRE, P. Ação cultural para a liberdade e outros escritos. S. Paulo: Ed. Paz e Terra, 2001.

FREIRE, P.; MACEDO, D. Um diálogo com Paulo Freire. In: McLAREN, P.; LEONARD, P.; GADOTTI, M. (Orgs.), Paulo Freire: poder, desejo e memórias da libertação. Porto Alegre: Ed. ArtMed, 1998, p. 203-210.

HENDERSON, E. Feminist pedagogy. In Gender and education association, 17 ago. 2016. Disponível em: http://www.genderandeducation.com/resources/pedagogies/feministpedagogy hooks, b. Teaching to transgress: education as the practice of freedom. New York: Routledge, 1994.

KONING, M. Lugares emergentes do sujeito-mulher: viagem com Paulo Freire e Maria de Lourdes Pintasilgo. Porto: Afrontamento, 2006.

LAMAS, R. Mulheres para além do seu tempo. Venda a Nova: Bertrand Editora, 1995.

LISTER, R. Citizenship: feminist perspectives. New York: New York University Press, 1997.

MACEDO, G.; AMARAL, A.L. A palavra, a identidade e a cultura translativa. Para uma introdução ao dicionário terminológico da crítica feminista. In: RAMALHO, M. I. e RIBEIRO, A. (Orgs.) Entre ser e estar: raízes, percursos e discursos da identidade. Porto: Afrontamento, 2002, p. 383-408. 
NÓBREGA, T. Qual lugar do corpo na educação? Notas sobre conhecimento, processos cognitivos e currículo. Educação e Sociedade, v. 26, n. 91, 2005, p. 599-615.

NOGUEIRA, C. Interseccionalidade e psicologia feminista. Salvador: Devires, 2017.

PINTASILGO, M. L. Prefácio. In: NÓVOA, A. e APPLE, M.W. Paulo Freire: política e pedagogia. Porto: Porto Editora, 1998.

ROMÃO, J.; ROMÃO, N. Pedagogia do oprimido: uma obra cinquentenária em evolução. In: MACEDO, E. (Org.). A educação como experiência ética, estética e solidária: buscando inspiração em Freire. Porto: IPFP, CIIE, FPCEUP. [no prelo]

SCOCUGLIA, A. A relevância do trabalho na África e a construção da práxis de Paulo Freire. In: MACEDO, E. (Org.). A educação como experiência ética, estética e solidária: buscando inspiração em Freire. Porto: IPFP, CIIE, FPCEUP. [no prelo]

SILVA, S.; ARAÚJO, H. Interrogando as masculinidades em contexto escolar: Mudança anunciada?. Ex-aequo, v. 15, 2007. p. 89-117.

WEBB, L.; WALKER, K.; BOLLIS, T. Feminist pedagogy in the teaching of research methods. International Journal of Social Research Methodology, v. 7, n. 5, 2004. p. 415-428.

WEILER, K. Freire and a feminist pedagogy of difference. Harvard Educational Review, v. 61, 1991, p. 449-474.

WEILER, K. Myths of Paulo Freire, Educational Theory, v. 46, n. 3, 1996, p. 353-371.

WEILER, K. Rereading Paulo Freire. In Kathleen Weiler (Ed.), Feminist engagements: Reading, resisting, and revisioning male theorists in education and cultural studies New York and London: Routledge, 2002, p. 67-87. WEILER, K. Freire e uma pedagogia feminista da diferença. ex-aequo, v. 8, 2004, p. 91-111.

YOUNG, I. Justice and the politics of difference. Princeton: Princeton University Press, 1990.

YOUNG, I. Intersecting voices: dilemmas of gender, political philosophy, and policy. Princeton: Princeton University Press, 1997.

Recebido em 30 de outubro de 2020.

Aprovado em 28 de dezembro de 2020.

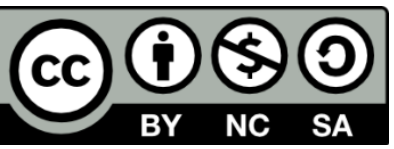

